\title{
Vasopressin Mechanism-Mediated Pressor Responses Caused by Central Angiotensin II in the Ovine Fetus
}

\author{
LIJUN SHI, CATALINA GUERRA, JIAMING YAO, AND ZHICE XU \\ Harbor-UCLA Medical Center and Research and Education Institute, Torrance, CA 90502 [L.S., C.G., \\ J.Y. Z.X.]; and Soochaw University School of Medicine, Suzhou 215007, China [Z.X.]
}

\begin{abstract}
AVP not only influences renal water excretion but also has profound cardiovascular effects in adults. Our recent studies have demonstrated that central angiotensin induced fetal pressor responses accompanied with AVP release. However, little is known of hormonal mechanisms in angiotensin-mediated fetal blood pressure (BP) changes. The present study determined AVP mechanisms in central angiotensin-mediated fetal pressor responses. The V1-receptor antagonist or V2-receptor antagonist was infused intravenously into the ovine fetus at $90 \%$ gestation. Angiotensin II (Ang II; $1.5 \mu \mathrm{g} / \mathrm{kg}$ ) was then injected intracerebroventricularly into the chronically instrumented fetus. Ang II produced a significant increase in fetal systolic, diastolic, and mean arterial pressure adjusted to amniotic pressure (A-MAP). The enhanced fetal A-MAP was associated with intense c-fos expression in the central putative cardiovascular area: the paraventricular nuclei $(\mathrm{PVN})$. Double labeling demonstrated that a number of the AVP-containing neurons in the PVN were expressing c-fos in response to central Ang II. Consistent with the activation of AVP neurons in the PVN, fetal plasma AVP was markedly enhanced. Fetal i.v. V1-receptor antagonist or V2-
\end{abstract}

\section{ABSTRACT}

receptor antagonist had no effect on either fetal or maternal baseline BP. However, intracerebroventricular Ang II-increased BP was partially inhibited, although not completely abolished, by the V1-receptor blockade. In contrast, fetal i.v. infusion of V2-receptor antagonist had no effect on the pressor responses induced by central Ang II. The results suggest that the central Ang II-mediated pressor responses at the last third of gestation is mediated partially by the AVP mechanism via V1 not V2 receptors. (Pediatr Res 56: 756-762, 2004)
Ang II, angiotensin II
AVP-ir, AVP-immunoreactivity
BP, blood pressure
FOS-ir, c-fos immunoreactivity
i.c.v., intracerebroventricular
MAP, mean arterial pressure
PVN, paraventricular nuclei
RAS, rennin-angiotensin system

Abbreviation

A-MAP, mean arterial pressure adjusted to amniotic pressure
The nonapeptide AVP, also known as antidiuretic hormone, has multiple actions, including water reabsorption and vasoconstriction in the periphery. This peptide also plays a role in cardiovascular diseases, including hypertension and congestive heart failure (1). In adults, plasma AVP has been reported to be elevated in some forms of hypertension, and this elevation correlates best with the severity of hypertension (2). Recent findings have demonstrated that the development of cardiovascular regulatory mechanisms starts before birth and that the in utero development of cardiovascular regulation is critical for fetal cardiovascular homeostasis $(3,4)$. Several peptides, including AVP and angiotensin

Received January 13, 2004; accepted April 15, 2004.

Correspondence: Zhice Xu, Ph.D., Harbor-UCLA Medical Center, 1124 West Carson Street, RB-1, Torrance, CA 90502; e-mail: zxuhice@ucla.edu

Research described in this article is supported by March of Dimes Research Grant, External Research Grant from Philip Morris USA Inc., and UCLA Faculty Grant Program Award to Z.X.

DOI: 10.1203/01.PDR.0000141519.85908.68
II (Ang II), are essential in the control of cardiovascular functions. Central renin-angiotensin system (RAS) plays an important role in the regulation of arterial pressure and in the development of certain forms of clinical and experimental hypertension $(3,5,6)$. Under certain conditions, the RAS and the AVP system operate as reciprocal mechanisms in the control of vascular resistance and arterial pressure in adults (7). For example, intracerebroventricular (i.c.v.) administration of Ang II causes a rise in blood pressure (BP) associated with AVP release (8-10). The pressor response induced by the i.c.v. Ang II in adults is partially related to an increase of AVP. In fetuses, previous study has shown that AVP plays a role in BP regulation during periods of hypovolemia (11). The enhanced plasma AVP contributed to a rise of mean arterial pressure (MAP) and decreased heart rate. I.v. infusion of the vasopressin V1-receptor blockade abolished the increase of the fetal MAP after application of AVP $(12,13)$.

Recent studies in our laboratory have demonstrated that i.c.v. Ang II increased fetal arterial pressure associated with an 
elevation of plasma AVP in the near-term ovine fetus (14). This raised a question of whether the Ang-mediated fetal pressor response was mediated by hormonal mechanisms. Therefore, the present study sought to determine the AVP mechanism in Ang-induced pressor responses and determine which subtype of AVP receptors may be involved. AVP is synthesized mainly in supraoptic nuclei and paraventricular nuclei (PVN) in the hypothalamus (3). Thus, we also sought to determine the hypothalamic AVP cellular activation under the condition of i.c.v. administration of Ang II in the near-term ovine fetus.

\section{METHODS}

Studies were performed in chronically instrumented fetal sheep at $90 \%$ of gestation. Animals were housed indoors in individual steel study cages and were acclimated to a 12:12-h light-dark cycle. Water and food (alfalfa pellets) were provided ad libitum. All surgical and experimental procedures have been approved by the Animal Care Committee.

Surgical preparation. For the surgical procedures, ketamine hydrochloride $(20 \mathrm{mg} / \mathrm{kg}$, i.m.) was injected in ewes. Anesthesia was maintained with $3 \%$ isoflurane and $1 \mathrm{~L} / \mathrm{min}$ oxygen. The uterus was opened over the fetal hindlimbs, and polyethylene catheters were placed in the maternal (inner diameter: 1.8 $\mathrm{mm}$; outer diameter: $2.3 \mathrm{~mm}$ ) and fetal (inner diameter: 1.0 $\mathrm{mm}$; outer diameter: $1.8 \mathrm{~mm}$ ) femoral vein and artery. An intrauterine catheter was inserted for measuring amniotic fluid pressure. An intracranial catheter was placed in one of the fetal lateral ventricles and held in place with dental cement as reported (15). Patency of the catheter at insertion was assessed by free flow of cerebrospinal fluid via gravity drainage. The placement of cannulae was finally verified with histologic analysis. The fetus was then returned to the uterus, and the uterus was closed using a double row of sutures. All catheters were led to the ewe's flank. The ends of the catheters were held in place in a small cloth pocket sutured to the skin of the ewe. During the initial $2 \mathrm{~d}$ of recovery, gentamicin $(8 \mathrm{mg})$ and oxacillin (33 mg) were administered intravenously to the fetus, and gentamicin (72 mg), oxacillin (1g), and chloramphenicol $(1 \mathrm{~g})$ were administered intravenously to the ewe (15). All animals were allowed $5 \mathrm{~d}$ for postoperative recovery.

Experimental protocol. On the testing day, sheep were allowed 60-100 min to acclimatize to the testing room. When maternal and fetal heart rates and arterial pressures seemed to be stable, a 30-min baseline of arterial pressure and heart rates was recorded.

Study 1: effect of i.c.v. Ang II on fetal cardiovascular responses, plasma AVP concentration, and c-fos expression in the hypothalamus. Studies began with a baseline ( -30 to 0 $\mathrm{min}$ ) followed by a study period (0 to $90 \mathrm{~min})$. Ang II (1.5 $\mu \mathrm{g} / \mathrm{kg}, 1 \mathrm{~mL}, n=5)$ or isotonic saline $(n=5)$ was then injected intracerebroventricularly over $2 \mathrm{~min}$ into the fetus ( $n$ $=5)$. Maternal/fetal blood samples $(4 \mathrm{~mL} / \mathrm{each})$ were drawn from the arterial catheters at $-30,-10,0$ (time of i.c.v. injection), 10, 25, 40, and 60 min for measurement of blood gases, hematocrit, plasma electrolytes, and AVP. Fetal blood samples were replaced with an equivalent volume of heparinized maternal blood withdrawn before the study.

Study 2: effect of i.v. V1- or V2-antagonist on the pressor response caused by central Ang II. Animals $(n=5)$ were assigned for three experimental treatments on separate days randomly. Study began with a baseline ( -30 to $0 \mathrm{~min}$ ) followed by a study period (0 to $90 \mathrm{~min}$ ) after i.c.v. Ang II (1.5 $\mu \mathrm{g} / \mathrm{kg}$ ) injection into the fetus, or, after the baseline ( -60 to $-20 \mathrm{~min}$ ) period, either [deamino-Pen ${ }^{1}, \mathrm{O}-\mathrm{Me}-\mathrm{Tyr}^{2}, \mathrm{Arg}^{8}$ ]vasopressin (a potent V1-antagonist; $10 \mu \mathrm{g} / \mathrm{kg}$; Sigma Chemical Co., St. Louis, MO) or [adamantaneacety $1^{1}$, O-Et- ${ }^{-}{ }^{-T y r}{ }^{2}$, $\mathrm{Val}^{4}$, aminobutyryl ${ }^{6}, \mathrm{Arg}^{8,9}$ ]-vasopressin (a potent V2antagonist; $150 \mu \mathrm{g} / \mathrm{kg}$; Sigma Chemical Co.), dissolved in 10 $\mathrm{mL}$ of $0.9 \% \mathrm{NaCl}$ saline, was infused into the fetal vein catheter for $30 \mathrm{~min}$ (i.e. from -20 to $10 \mathrm{~min}$ ) by an infusion pump, Ang II $(1.5 \mu \mathrm{g} / \mathrm{kg})$ was then injected intracerebroventricularly into the fetus at $0 \mathrm{~min}$. The doses of the drugs were referred to in previous reports $(16-18)$. Blood samples $(4 \mathrm{~mL}$ each) were withdrawn from the fetal and maternal arterial catheters at $-30,-10,0,10,25,40$, and $60 \mathrm{~min}$ for measurements of blood gases, hematocrit, plasma osmolality, plasma electrolytes, and AVP.

Throughout studies, maternal/fetal systolic and diastolic pressure, heart rate, and amniotic pressure were recorded continuously. The fetal MAP was corrected against amniotic fluid pressure. Fetal and maternal BP was measured by means of a Beckman R612 (Beckman Instruments, Fullerton, CA) physiologic recorder with Statham (Garret, Oxnard, CA) P23 transducers. BP and heart rate were determined by computer analysis of waveforms using a customized pattern recognition algorithm.

Arterial blood values and AVP analysis. Arterial $\mathrm{pH}$, blood gases $\left(\mathrm{Po}_{2}, \mathrm{P}_{\mathrm{CO}_{2}}\right)$, and $\mathrm{Hb}$ were measured with a Radiometer BM 33 MK2-PHM 72 MKS acid-base analyzer system (Radiometer, Copenhagen, Denmark). Plasma osmolality was measured on an Advanced Digimatic osmometer (Advanced Instruments, Needham Heights, MA). Plasma $\mathrm{Na}^{+}, \mathrm{K}^{+}$, and $\mathrm{Cl}^{-}$ concentrations were determined by a Nova analyzer (Nova Biomedical, Waltham, MA).

The blood samples were collected into iced tubes that contained lithium heparin and centrifuged immediately for AVP RIA. Plasma AVP concentrations were measured using SepPak C18 cartridge (Waters Associates, Milford, MA) extraction (19). Sensitivity of the AVP antiserum is $1.5 \mathrm{pg} / \mathrm{tube}$ with intra-assay and interassay coefficients of variation of 6 and $8 \%$, respectively. AVP recoveries average $70 \%$ in our experiments.

Double-labeling experiments. At the conclusion of study 1, animals were anesthetized as described above. A middle abdominal incision was made. The fetal head and neck were exposed, and one fetal carotid artery was catheterized with an 18 -gauge needle. The fetuses were perfused via the carotid artery with $0.01 \mathrm{M}$ of PBS followed by $4 \%$ paraformaldehyde in $0.1 \mathrm{M}$ of phosphate buffer. Twenty-microgram coronal sections of the fetal forebrain were obtained using a cryostat. Every other section of the hypothalamus was used for c-fos immunoreactivity (FOS-ir) staining using the avidin-biotinperoxidase technique (15). The tissue sections were incubated on a gentle shaker overnight in the primary antibody $(1: 15,000$; 
Santa Cruz Biotechnology, Santa Cruz, CA). The sections were further incubated in goat anti-rabbit serum (1:500) for $1 \mathrm{~h}$ and processed using the Vectastain ABC kit (Vector Labs, Burlingame, CA). The sections were then treated with $1 \mathrm{mg} / \mathrm{mL}$ of diaminobenzidine tetrahydrochloride (Sigma Chemical Co.; $0.02 \%$ hydrogen peroxide).

For characterizing the positive FOS-ir cells in the PVN, the hypothalamic sections were then rinsed for $5 \mathrm{~min}$ in a $0.5 \%$ solution of $\mathrm{H}_{2} \mathrm{O}_{2}$ in $0.01 \mathrm{M}$ of PBS and $20 \mathrm{~min}$ in the blocking serum (1:500; Vector Labs). The sections were then incubated in the AVP antibody (1:5,000; Diasorin) overnight, after which an anti-rabbit antibody was applied. Nickel-diaminobenzidine was used as chromogen. The sections were dried, dehydrated in alcohol, and then coverslipped with histologic mounting medium (National Diagnostics, Atlanta, GA).

Data analysis. All analog signals for fetal cardiovascular data were recorded continuously throughout the study and digitized with Win-DAQ acquisition software (DataQ Instruments, Akron, $\mathrm{OH})$. Heart rate, systolic and diastolic BP, and MAP were calculated from the pressure waveforms by means of Advanced CODAS software. Number of FOS-ir-positive cells was evaluated in a blinded manner (15). Total number of AVP-ir-positive neurons and number of FOS-ir together with AVP-ir were counted in the PVN. Statistical analysis was performed with repeated measures ANOVA. Comparisons were determined with one-way ANOVA followed by the post $h o c$ Tukey test. Paired $t$ test was used to analyze the FOS-ir staining between i.c.v. vehicle and i.c.v. Ang II. All data were expressed as mean $\pm \mathrm{SEM}$.

\section{RESULTS}

Blood values. Histologic analysis confirmed that all i.c.v. cannulae were inserted into the fetal lateral ventricle. In the control and the experimental animals, i.c.v. Ang II or vehicle had no effect on arterial $\mathrm{pH}$, blood gases $\left(\mathrm{PO}_{2}, \mathrm{PCO}_{2}\right)$, hemato- crit, $\mathrm{Hb}$, plasma osmolality, and electrolyte $\left(\mathrm{Na}^{+}, \mathrm{K}^{+}\right.$, and $\mathrm{Cl}^{-}$) concentrations in either maternal or fetal animals (all $p>$ 0.05 ). There was no significant difference in blood values after treatment with the V2-blocker on comparing before and after i.c.v. Ang II (all $p>0.05$ ). Fetal i.v. infusion of V1-receptor antagonist and i.c.v. injection of Ang II also had no effect on fetal arterial blood values (Table 1).

Cardiovascular responses. In study 1, there was no significant difference between the control and the experimental group for maternal systolic BP $\left(\mathrm{F}_{8,1}=0.17\right)$, diastolic $\mathrm{BP}\left(\mathrm{F}_{8,1}\right.$ $=0.12)$, and heart rate $\left(\mathrm{F}_{8,1}=2.17\right.$; all $\left.p>0.05\right)$. However, i.c.v. Ang II significantly increased fetal BP (Fig. 1). Fetal systolic and diastolic BP and MAP were increased in the experimental animals compared with the control fetuses $\left(\mathrm{F}_{8,1}\right.$ $=4.95,1.71$, and 3.27, respectively; all $p<0.01$ ). In the experimental group, fetal adjusted MAP (A-MAP) was increased from the baseline level $(46.8 \pm 1.49 \mathrm{~mm} \mathrm{Hg}$ to $58.2 \pm$ $3.42 \mathrm{~mm} \mathrm{Hg}$ ) at $10 \mathrm{~min}$ after i.c.v. injection of Ang II. This was a $24.4 \%$ increase from the baseline. The increased systolic BP, diastolic BP, and A-MAP lasted for at least $40 \mathrm{~min}$. In the control animals, the i.c.v. vehicle had no effect on fetal systolic and diastolic BP and A-MAP (all $p>0.05$ ). Fetal and maternal heart rates were not changed by the i.c.v. Ang II in the fetus $\left(\mathrm{F}_{8,1}=0.19, \mathrm{~F}_{8,1}=0.25\right.$, respectively; both $\left.p>0.05\right)$.

In study 2, neither fetal i.c.v. Ang II nor i.c.v. Ang II in the presence of V1-receptor antagonist or V2-receptor antagonist affected maternal systolic and diastolic BP, MAP, and heart rate (all $p>0.05$, the baseline period versus the period after i.c.v. Ang II). After i.c.v. Ang II, the fetal systolic BP, diastolic $\mathrm{BP}$, and A-MAP were immediately elevated $\left(\mathrm{F}_{32,7}=3.30\right.$, $\mathrm{F}_{32,7}=4.17, \mathrm{~F}_{32,7}=3.98$; all $\left.p<0.01\right)$. Fetal A-MAP was increased from the baseline level $(46.7 \pm 1.07 \mathrm{~mm} \mathrm{Hg}$ to 57.6 $\pm 1.92 \mathrm{~mm} \mathrm{Hg}$ ), a $23.3 \%$ increase from the baseline A-MAP. The increased systolic and diastolic BP and A-MAP lasted for at least $40 \mathrm{~min}$. I.v. infusion of V1-receptor antagonist or

Table 1. Effect of V1-receptor antagonist on fetal arterial values in response to i.c.v. Ang II

\begin{tabular}{|c|c|c|c|c|c|c|}
\hline & $-30 \mathrm{~min}$ & $-10 \mathrm{~min}$ & $10 \mathrm{~min}$ & $25 \mathrm{~min}$ & $40 \mathrm{~min}$ & $60 \mathrm{~min}$ \\
\hline \multicolumn{7}{|c|}{ Het $(\%)$} \\
\hline (1) & $27.7 \pm 1.4$ & $27.3 \pm 1.1$ & $27.2 \pm 1.5$ & $27.6 \pm 1.0$ & $28.0 \pm 1.9$ & $27.1 \pm 2.0$ \\
\hline (2) & $27.3 \pm 0.9$ & $26.5 \pm 1.6$ & $26.7 \pm 1.4$ & $27.2 \pm 1.0$ & $27.4 \pm 1.3$ & $26.6 \pm 1.2$ \\
\hline (1) & $7.34 \pm 0.01$ & $7.35 \pm 0.02$ & $7.32 \pm 0.01$ & $7.33 \pm 0.01$ & $7.34 \pm 0.01$ & $7.36 \pm 0.02$ \\
\hline (2) & $7.37 \pm 0.01$ & $7.36 \pm 0.02$ & $7.36 \pm 0.01$ & $7.38 \pm 0.01$ & $7.36 \pm 0.01$ & $7.37 \pm 0.01$ \\
\hline \multicolumn{7}{|c|}{$\mathrm{Po}_{2}(\mathrm{~mm} \mathrm{Hg})$} \\
\hline \multicolumn{7}{|c|}{ Osmolality (mosmol/kg) } \\
\hline (1) & $304.2 \pm 2.1$ & $303.4 \pm 2.0$ & $303.8 \pm 1.7$ & $301.4 \pm 0.9$ & $302.6 \pm 2.4$ & $303.6 \pm 1.6$ \\
\hline (2) & $303.8 \pm 3.1$ & $302.7 \pm 2.1$ & $304.7 \pm 2.3$ & $303.5 \pm 1.9$ & $302.4 \pm 1.8$ & $303.7 \pm 2.3$ \\
\hline \multicolumn{7}{|c|}{$\mathrm{Na}^{+}(\mathrm{mEq} / \mathrm{L})$} \\
\hline (1) & $142.1 \pm 1.4$ & $142.8 \pm 0.9$ & $142.9 \pm 0.5$ & $142.3 \pm 0.8$ & $142.3 \pm 1.0$ & $143.1 \pm 0.6$ \\
\hline (2) & $141.2 \pm 0.6$ & $141.4 \pm 0.8$ & $142.4 \pm 0.6$ & $142.8 \pm 1.1$ & $142.3 \pm 0.9$ & $141.0 \pm 1.1$ \\
\hline (1) & $109.7 \pm 1.2$ & $110.8 \pm 1.2$ & $110.3 \pm 0.9$ & $108.9 \pm 1.0$ & $109.3 \pm 1.4$ & $110.6 \pm 0.7$ \\
\hline (2) & $110.1 \pm 1.4$ & $109.9 \pm 1.3$ & $109.7 \pm 0.8$ & $109.0 \pm 1.3$ & $110.7 \pm 0.8$ & $108.9 \pm 0.6$ \\
\hline
\end{tabular}

(1), i.c.v. Ang II; (2), i.c.v. Ang II during the i.v. infusion of V1-antagonist; Hct, hematocrit. 

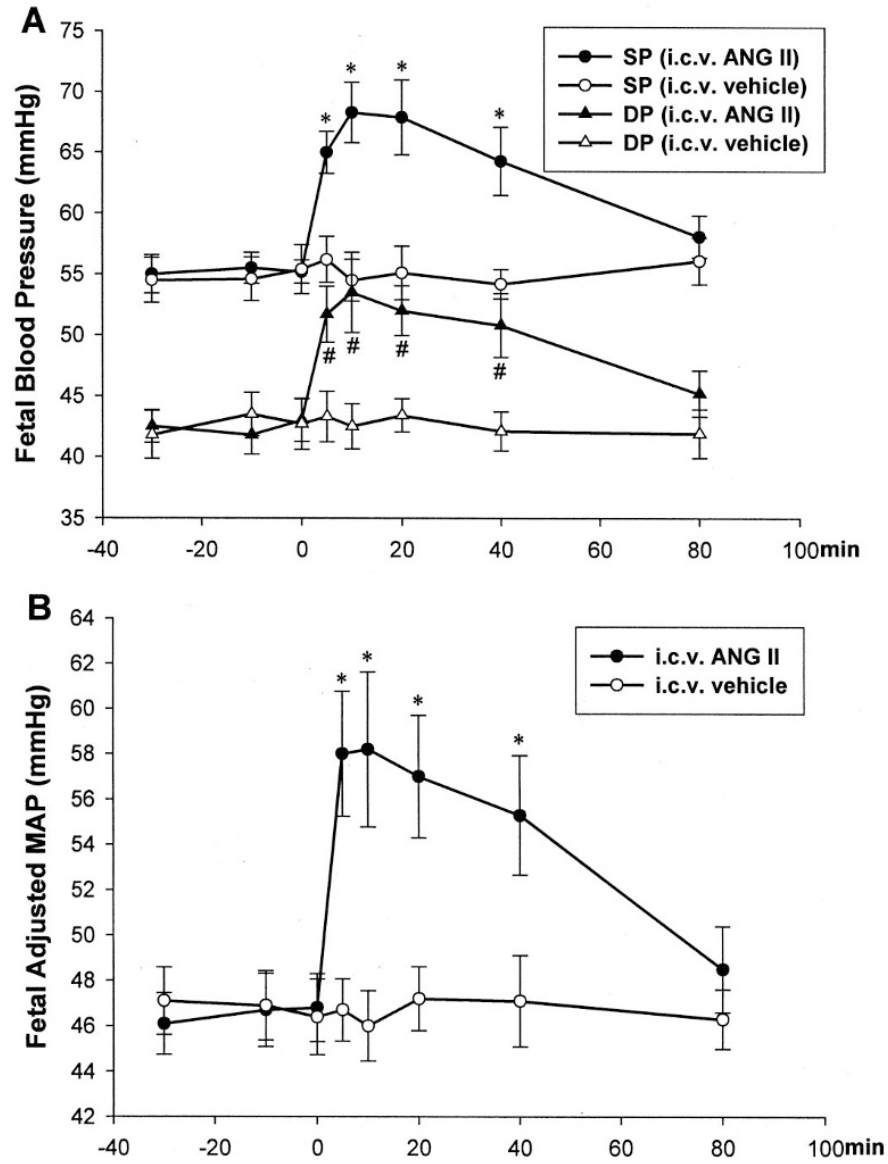

Figure 1. The effect of i.c.v. vehicle or Ang II $(1.5 \mu \mathrm{g} / \mathrm{kg})$ on fetal systolic BP, diastolic BP $(A)$, and A-MAP $(B) .0$ min, time for i.c.v. injection. ${ }^{*} p<$ 0.01, vs baseline level; SP, systolic BP; DP, diastolic BP.

V2-receptor antagonist did not change the fetal baseline BP (Fig. 2). With the treatment of i.v. V1-receptor antagonist, i.c.v. Ang II still increased the fetal systolic BP, diastolic BP, and A-MAP $\left(\mathrm{F}_{32,7}=2.99, \mathrm{~F}_{32,7}=4.01, \mathrm{~F}_{32,7}=3.15\right.$; all $p<$ 0.01). However, there was a significant difference of fetal A-MAP between the i.c.v. Ang II only and i.c.v. Ang II in the presence of i.v. V1-receptor antagonist $\left(\mathrm{F}_{8,1}=3.20, p<0.01\right)$. In the face of combination of i.v. V1 blocker and i.c.v. Ang II, fetal A-MAP also reached the peak at $10 \mathrm{~min}$ (from the baseline $46.3 \pm 1.2 \mathrm{~mm} \mathrm{Hg}$ to $53.1 \pm 1.6 \mathrm{~mm} \mathrm{Hg}$ ). The percentage increase of A-MAP was $14.7 \%$, which was a $36.9 \%$ decrease compared with that of the i.c.v. Ang II only (23.3\%). The increased A-MAP lasted for 20 min. As shown in Fig. 2, the treatment of i.v. V2-receptor antagonist had no effect on i.c.v. Ang II-increased fetal A-MAP $\left(\mathrm{F}_{8,1}=0.94, p>0.05\right)$. The fetal and maternal heart rates were not changed by the treatments (all $p>0.05$, the baseline period versus the period after i.c.v. injection of Ang II).

Plasma AVP assay. There was no change in plasma AVP levels between the control and the experimental ewes $\left(\mathrm{F}_{8,1}=\right.$ $0.76, p>0.05)$. However, the fetal AVP concentrations were significantly higher in the i.c.v. Ang II injected-fetuses than in the i.c.v. vehicle-treated animals $\left(\mathrm{F}_{8,1}=7.21, p<0.05\right)$. In the control group, i.c.v. vehicle did not change the maternal and fetal plasma AVP $\left(\mathrm{F}_{28,6}=0.92\right.$ and 0.47 , respectively; $p>$

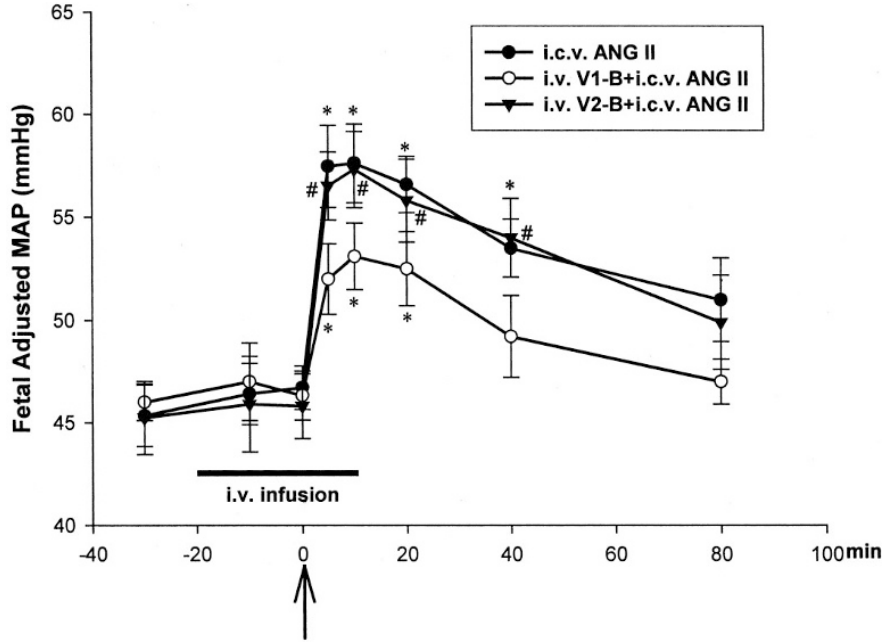

Figure 2. The effect of the i.v. infusion of V1- or V2-receptor antagonist on fetal A-MAP increased by i.c.v. Ang II $(1.5 \mu \mathrm{g} / \mathrm{kg})$. The arrow stands for the time for i.c.v. injection of Ang II. *\#p $<0.01 v s$ baseline level. V1-B, the V1-receptor blocker; V2-B, the V2-receptor blocker.

0.05 , baseline period versus period after i.c.v. injection). However, the i.c.v. Ang II significantly increased fetal plasma AVP $\left(\mathrm{F}_{28,6}=4.25, p<0.01\right.$; Fig. $3 A$ ) by 5.8 times (from $2.6 \pm 1.2$ to $15.2 \pm 3.7 \mathrm{pg} / \mathrm{mL}$ ) at $10 \mathrm{~min}$, and a peak level was observed at $25 \mathrm{~min}$ (8.8 times, from $3.0 \pm 1.2$ to $26.0 \pm 4.8 \mathrm{pg} / \mathrm{mL}$ ) after i.c.v. Ang II. Plasma fetal AVP then dropped at 40 and $60 \mathrm{~min}$ after injection. The V1- and V2-antagonist had no influence on i.c.v. Ang II-increased fetal AVP $\left(\mathrm{F}_{8,1}=14.26, \mathrm{~F}_{8,1}=7.96\right.$, respectively; both $p>0.05$; Fig. $3 B$ ).

FOS-AVP double labeling. In control fetuses that were treated with i.c.v. vehicle, there was little FOS-ir in the PVN. However, i.c.v. Ang II produced intense FOS-ir in the PVN. There was significant difference of FOS-ir between i.c.v. vehicle- and i.c.v. Ang II-injected fetuses $(t=9.27 ; p<0.01)$. Ang II-induced FOS-ir was detected in both magnocellular and parvicellular parts of the PVN.

Positive AVP-ir was detected in the PVN. There was no difference in the total counts of AVP-ir in the PVN between the control and the experimental fetuses $(t=2.31, p>0.05)$. In the control fetus, little FOS-ir was present in the PVN, and there was no co-localization of AVP-ir and FOS-ir. However, the i.c.v. Ang II increased FOS-ir in the bilateral PVN. Many positive FOS-ir were located in the paraventricular AVP-ir neurons. Double labeling of FOS-ir and AVP-ir was significantly higher in the i.c.v. Ang II-injected fetuses than in the control animals $(t=5.78, p<0.01$; Fig. 4). Approximately $58 \%$ of the AVP-containing neurons co-localized with positive FOS-ir in the PVN.

\section{DISCUSSION}

The present study demonstrated that i.c.v. Ang II induced a marked neuronal activation in the AVP-containing neurons of the fetal PVN. Consistent with the AVP neuronal activation, the fetal plasma AVP concentrations were significantly elevated. Most important, i.v. infusion of an AVP V1-receptor antagonist produced a partial inhibition of the pressor response 

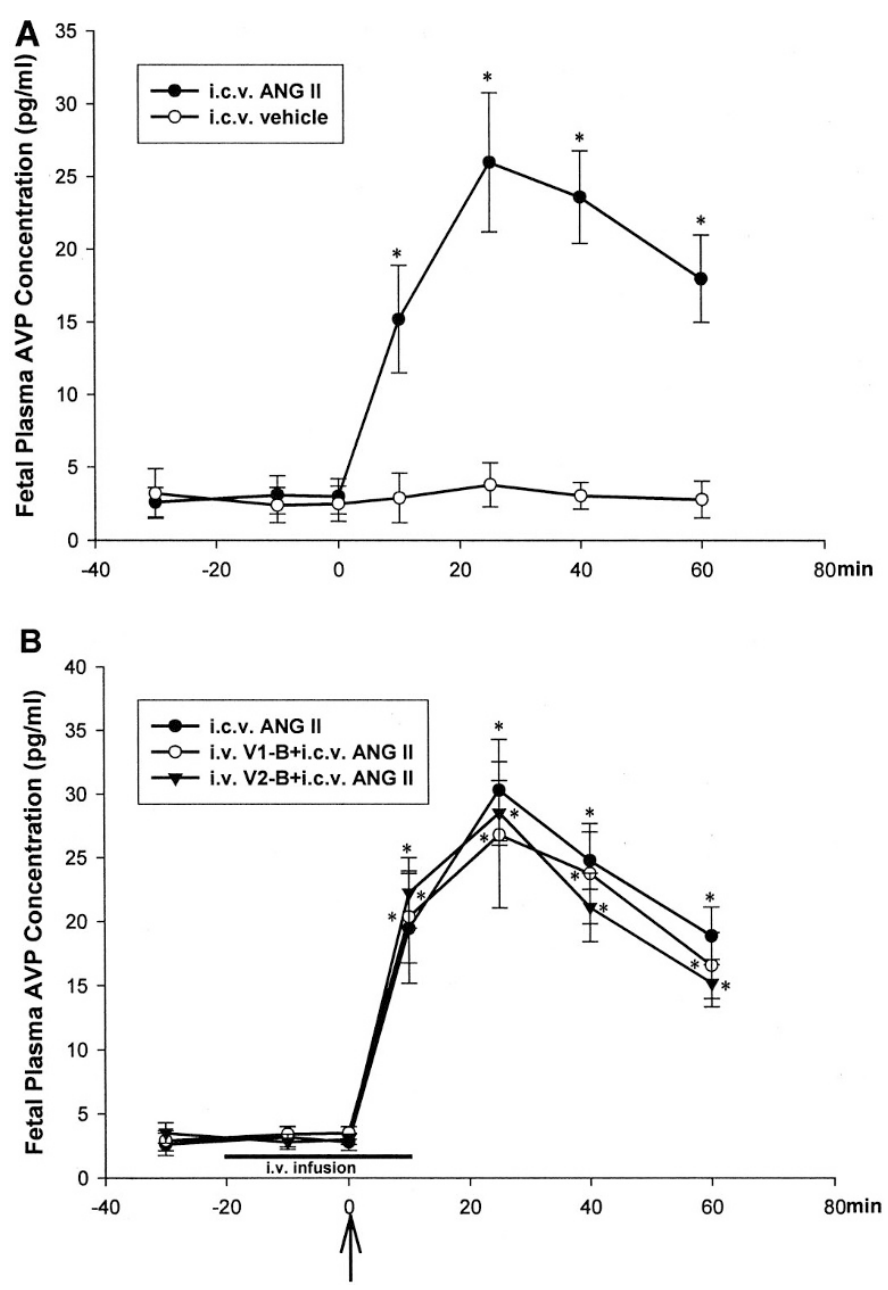

Figure 3. (A) The effect of i.c.v. injection of vehicle or Ang II $(1.5 \mu \mathrm{g} / \mathrm{kg})$ on fetal plasma AVP levels. (B) The effect of the i.v. infusion of V1- or V2-receptor antagonist on the increase of fetal plasma AVP induced by i.c.v. Ang II $(1.5 \mu \mathrm{g} / \mathrm{kg}) . * p<0.01$ vs baseline level. V1-B, the V1-receptor blocker; V2-B, the V2-receptor blocker.

induced by i.c.v. Ang II, whereas the V2-blocker had no effect on the Ang-mediated fetal BP changes. The data support the hypothesis that the increased AVP subsequent to i.c.v. Ang II plays a role in the central Ang-mediated pressor responses in utero.

Central RAS is important in the control of cardiovascular homeostasis. In adults, there is significant information regarding central actions of Ang $(6,8)$. I.c.v. Ang II has been shown repeatedly to produce reliable pressor and neuroendocrine responses (e.g. AVP release) in adults $(20,21)$. Our recent studies have shown that i.c.v. Ang II caused an increase of fetal arterial pressure in association with an increase of plasma AVP (14). The present study investigated the relationship between hormone mechanisms and fetal pressor responses after central application of Ang II. After i.c.v. Ang II, fetal systolic BP, diastolic BP, and A-MAP significantly increased within $5 \mathrm{~min}$ as reported (13). The results of the endocrine experiments showed that the fetal plasma AVP was enhanced within $10 \mathrm{~min}$ and the increased level was 8.8 times at 20 min after i.c.v. Ang II.
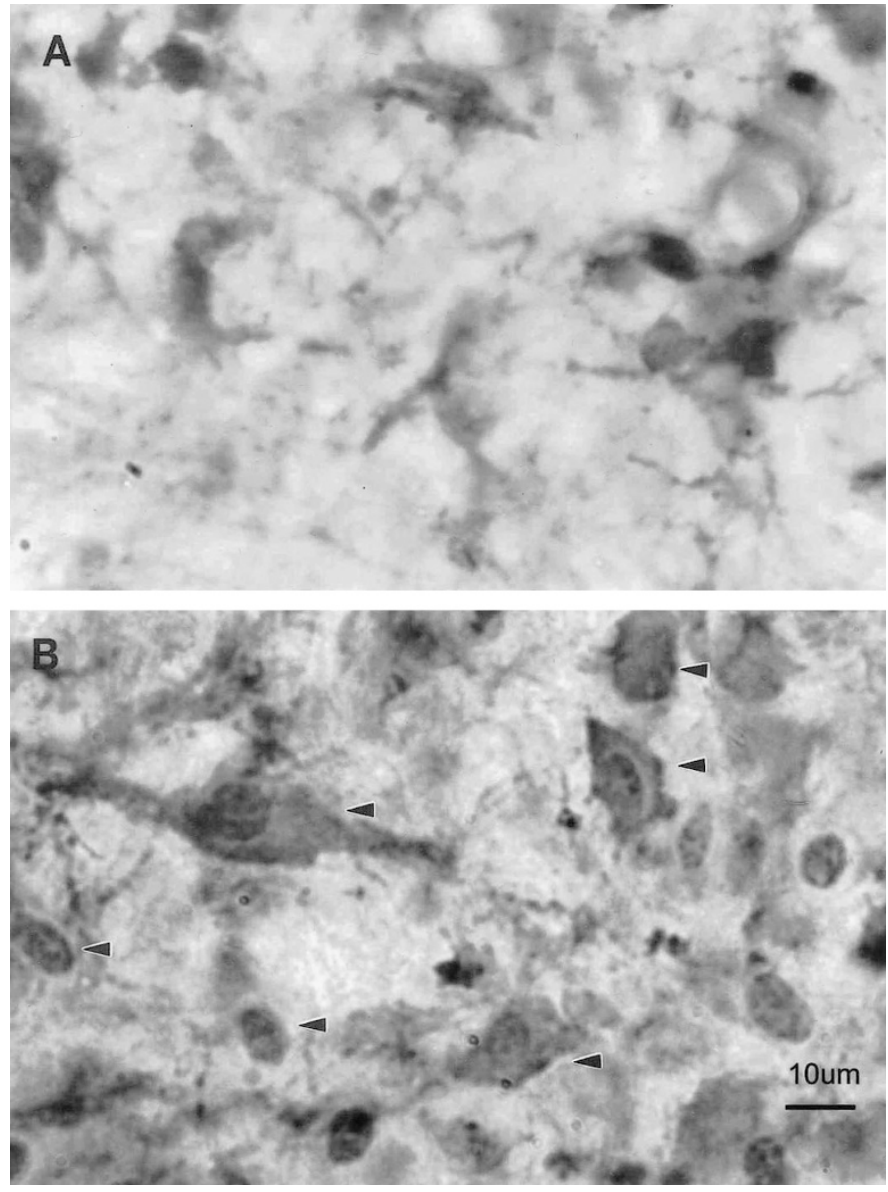

Figure 4. Double labeling of FOS-ir and AVP-ir in the paraventricular nuclei. (A) The control fetus infused with vehicle. (B) The fetus injected i.c.v. Ang II $(1.5 \mu \mathrm{g} / \mathrm{kg})$. Arrows show co-localization of FOS-ir and AVP-ir. Magnification: $\times 100$.

AVP is a major hormone of water conservation through its physiologic antidiuretic effect. AVP also has a vasopressor effect at high doses (1). It is synthesized in the hypothalamic magnocellular cells (22). In general, AVP does not cross the placental barrier (23). The hypothalamic paraventricular and supraoptic neurons are main sites that synthesize AVP, and their axonal processes constitute the secretory portion of the mammalian posterior pituitary from which this hormone is released. Release of AVP from neurohypophysis is influenced by several variables; the most important among them are osmotic and volume factors (24). I.v. hypertonic $\mathrm{NaCl}$ increased fetal plasma osmolality and sodium, which resulted in activation of AVP neurons and an increase of plasma AVP at near term (25). In the present study, the fetal physiologic status remained stable under the condition of i.c.v. Ang II as arterial values $\left(\mathrm{pH}, \mathrm{PO}_{2}, \mathrm{PcO}_{2}\right.$, and plasma electrolytes) were not changed. Particularly, the unchanged fetal plasma osmolality and sodium levels indicate that the osmotic mechanism was unlikely involved in the fetal AVP release.

Vasopressin secretion can be influenced by changes in blood volume and pressure (24). Hypotension and hypovolemia provoke an increase of AVP. Typically, hemorrhage increased plasma AVP (26). In the present study, fetal blood hematocrit and $\mathrm{Hb}$ were not influenced by the central administration of 
Ang II, indicating unchanged fluid volume. In addition, hypotension facilitates whereas hypertension inhibits AVP release (27). The fetal BP was increased after i.c.v. Ang II. This does not support the possibility that the alteration of fetal BP may cause the increase of fetal plasma AVP.

In addition to osmotic and volume mechanisms, an increase of AVP concentration is facilitated by both central and peripheral Ang II $(8,28,29)$. Our recent study demonstrated that i.c.v. Ang II in the near-term ovine fetuses increased fetal plasma AVP (15). Double staining of FOS-ir and AVP-ir in the PVN was conducted in the present study. To our knowledge, it is the first study to demonstrate that AVP-containing neurons in the PVN were activated with c-fos expression by the central Ang II. This provides direct evidence of activation of the AVP neurons in response to Ang II in the fetal brain.

A number of studies support the concept that two interacting systems in the brain are responsible for Ang-increased arterial pressure: autonomic and hormonal mechanisms. Several hormonal factors, particularly AVP, may contribute to Angmediated pressor responses. In adults, i.c.v. Ang II caused not only an increase of plasma AVP but also an enhancement of BP $(8,9,30,31)$. In the present study, it is noted that there was a significant increase of fetal plasma AVP after i.c.v. Ang II, accompanied with activation of AVP neurons. It has been demonstrated that the increase of plasma AVP could enhance fetal MAP and decrease heart rate. I.v. infusion of the V1receptor blockade abolished AVP-increased MAP $(12,32)$. To explore the hormonal mechanism-mediated pressor responses, we used a V1- antagonist. Biologic effects of AVP are mediated by three receptor subtypes: V1, V2, and V3 that are located in different sites with different physiologic functions (24). The V1-receptors are mainly present in smooth muscle vascular cells with a ubiquitous vasoconstrictive effect. The V2-receptors are involved in water reabsorption in the kidney. The V3-receptors are expressed in the pituitary, regulating ACTH secretion. Selective blockade of V1 receptors is a potential therapy for hypertension, congestive heart failure, and peripheral vascular disease (33).

I.v. V1- or V2- receptor antagonist did not change the baseline BP and heart rate of the fetus. This indicates that endogenous AVP at basal levels may not play a significant role in the maintenance of the cardiovascular homeostasis in utero. However, the V1-receptor antagonist inhibited the Ang IIinduced pressor response in the near-term fetus. Although the treatment of i.v. V1-receptor antagonist significantly decreased the pressor response, the increased fetal A-MAP by i.c.v. Ang II was not completely reduced. The increased level of fetal A-MAP after i.c.v. Ang II was decreased $36.9 \%$ by the V1antagonist. In addition, the duration of i.c.v. Ang II-increased fetal BP was decreased by the pretreatment of the V1 antagonist. In contrast, fetal i.v. infusion of the V2-receptor antagonist had no effect on the pressor response induced by central Ang II. The doses of the V2 antagonist was high enough as reported before (18). The V2 receptors are mainly located at the kidneys, whereas the $\mathrm{V} 1$ receptors are dominant in blood vessels (33). It seems that vascular resistance may be a key factor for the AVP-mediated fetal pressor effect after administration of central Ang II. These data indicate that the Ang- increased AVP contributes partially to the central RASmediated pressor responses and the V1- rather than the V2receptor mechanism is involved.

As mentioned above, autonomic mechanisms are also major contributors to the i.c.v. Ang II-increased BP (34). There are extensive interactions between the RAS and sympathetic system in the control of cardiovascular homeostasis (35). The PVN, with rich Ang receptors, is known as a critical site of cardiovascular regulation (36). Ang II acts on the PVN to augment the cardiac sympathetic reflex (37). In the present study, the neural activity marked with c-fos in the PVN, particularly in the parvicellular part of this nucleus, suggests that sympathetic pathways in the fetal PVN has matured enough in response to i.c.v. Ang II in the control of BP.

Precise control over the cardiovascular system requires the integration of both neuronal and hormonal signals related to BP. Hormonal signals, which are slow and long-lasting, interacting with the neuronal system, which is fast and transient, modulate the efferent mechanisms that ultimately determine the level of vascular pressure and volume. In response to the peripheral V1-receptor blockade, in the present study, the pressor response caused by central Ang II was decreased, which was shorter than that without the treatment of the V1 antagonist.

Taken together, there are two findings in the present study. Ang II-induced FOS-ir in the AVP-containing neurons in the PVN is novel evidence at the cellular level for activation of the central AVP system via the brain RAS. In addition, we demonstrated that the increased AVP subsequent to the i.c.v. Ang II plays a partial role in the central Ang-mediated pressor responses in fetuses. The V1- rather than the V2-receptors contribute to the AVP-mediated pressor response after central Ang II. The data provide information on the hormonal and the receptor mechanisms in the brain RAS-regulated BP.

\section{REFERENCES}

1. Matsuhisa A, Taniguchi N, Koshio H, Yatsu T, Tanaka A 2000 Nonpeptide arginine vasopressin antagonists for both V1A and V2 receptors: synthesis and pharmacological properties of 4-(1,4,5,6-tetrahydroimidazo [4,5-d][1] benzoazepine-6-carbonyl) benzanili de derivatives and 4'-(5,6-dihydro-4H-thiazolo[5,4-d][1]benzoazepine-6carbonyl)benzanilide derivatives. Chem Pharm Bull (Tokyo) 48:21-31

2. Johnston CI 1985 Vasopressin in circulatory control and hypertension. J Hypertens 3:557-569

3. Langley-Evans SC, Sherman RC, Welham SJ, Nwagwu MO, Gardner DS, Jackson AA 1999 Intrauterine programming of hypertension: the role of the renin-angiotensin system. Biochem Soc Trans 27:88-93

4. Woods LL 2000 Fetal origins of adult hypertension: a renal mechanism? Curr Opin Nephrol Hypertens 9:419-425

5. Allikmets K, Parik T, Viigimaah M 1999 The renin-angiotensin system in essential hypertension: associations with cardiovascular risk. Blood Press 8:70-78

6. Neutel JM, Smith DH 1999 Hypertension control: multifactorial contributions. Am J Hypertens 12:164S-169S

7. McNeill JR 1983 Role of vasopressin in the control of arterial pressure. Can J Physiol Pharmarcol 61:1226-1235

8. Fitzsimons JT 1998 Angiotensin, thirst, and sodium appetite. Physiol Rev 78:583686

9. Ganten D, Hutchinson JS, Schelling P, Ganten U, Fischer H 1976 The iso-renin angiotensin systems in extrarenal tissue. Clin Exp Pharmacol Physiol 3:103-126

10. Phillips MI 1987 Functions of angiotensin in the central nervous system. Annu Rev Physiol 49:413-435

11. Kelly RT, Rose JC, Meis PJ, Hargrave BY, Morris M 1983 Vasopressin is important for restoring cardiovascular homeostasis in fetal lambs subjected to hemorrhage. Am J Obstet Gynecol 146:807-812

12. Ervin MG, Ross MG, Leake RD, Fisher DA 1992 V1- and V2-receptor contributions to ovine fetal renal and cardiovascular responses to vasopressin. Am J Physiol 262:R636-R643 
13. Wright JW, Harding JW 1992 Regulatory role of brain angiotensin in the control of physiological and behavioral responses. Brain Res Brain Res Rev 17:227-262

14. Xu Z, Shi L, Hu F, White R, Stewart L, Yao J 2003 In utero development of centra ANG-stimulated pressor response and hypothalamic fos expression. Brain Res Dev Brain Res 145:169-176

15. Xu Z, Calvario G, Yao J, Day L, Ross MG 2001 Central angiotensin induction of feta brain c-fos expression and swallowing activity. Am J Physiol 280:R1837-R1843

16. Apostolakis EM, Longo LD, Yellon SM 1991 Regulation of basal adrenocorticotropin and cortisol secretion by arginine vasopressin in the fetal sheep during late gestation. Endocrinology 129:295-300

17. Ullman J, Eriksson S, Rundgren M 2001 Effects of losartan, prazosin and a vasopressin V1-receptor antagonist on renal and femoral blood flow in conscious sheep. Acta Physiol Scand 171:99-104

18. Haselton JR, Vari RC 1998 Neuronal cell bodies in paraventricular nucleus affect rena hemodynamics and excretion via the renal nerves. Am J Physiol 275:R1334-R1342

19. Kullama LK, Ross MG, Lam R, Leake RD, Ervin MG, Fisher DA 1992 Ovine maternal and renal vasopressin receptor response to maternal dehydration. Am J Obstet Gynecol 167:1717-1722

20. Challis JR, Mitchell BF 1983 Endocrinology of pregnancy and parturition. In: Warshaw JB (ed) The Biological Basis of Reproductive and Developmental Medicine. Elsevier Press, New York, pp 106

21. Siegel SR, Oaks G, Palmer S 1981 Effects of angiotensin II on blood pressure, plasm renin activity, and aldosterone in the fetal lamb. Dev Pharmacol Ther 3:144-149

22. Birnbaumer M 2000 Vasopressin receptors. Trends Endocrinol Metab 11:406-410

23. Saunders NR, Knott GW, Dziegielewska KM 2000 Barriers in the immature brain. Cell Mol Neurobiol 20:29-40

24. Gonzalez Chon O, Garcia Lopez SM 2002 Vasopressin: uses in cardiovascula practice. Arch Cardiol Mex 72:249-260

25. Xu Z, Nijland MJ, Ross MG 2001 Plasma osmolality dipsogenic thresholds and c-fos expression in the near-term ovine fetus. Pediatr Res 49:678-685
26. Thrasher TN, Keil LC 2000 Systolic pressure predicts plasma vasopressin responses to hemorrhage and vena caval constriction in dogs. Am J Physiol 279:R1035-R1042

27. Johnson AK, Edward GL1990 The neuroendocrinology of thirst: afferent signaling and mechanisms of central integration. In: Pfaff DW, Ganten D (eds) Current Topics in Neuroendocrinology. Springer-Verlag, Berlin, pp 149-190

28. Hjelmqvist H, Rundgren M 1990 Effect of intracerebroventricular deuterium oxide on water intake and AVP release induced by intravenous infusion of angiotensin II in sheep. Acta Physiol Scand 138:155-160

29. Leng G, Dyball RE, Luckman SM 1992 Mechanisms of vasopressin secretion. Horm Res 37:33-38

30. Phillips MI 1978 Angiotensin in the brain. Neuroendocrinology 25:354-377

31. Severs WB, Daniels-Severs AE 1973 Effects of angiotensin on the central nervous system. Pharmacol Rev 25:415-449

32. Nuyt AM, Segar JL, Holley AT, O’Mara MS, Chapleau MW, Robillard JE 1996 Arginine vasopressin modulation of arterial baroreflex responses in fetal and newborn sheep. Am J Physiol 271:R1643-R1653

33. Thibonnier M, Coles P, Thibonnier A, Shoham M 2001 The basic and clinical pharmacology of nonpeptide vasopressin receptor antagonists. Annu Rev Pharmacol Toxicol 41:175-202

34. Clark KE, Irion GL, Mack CE 1990 Differential responses of uterine an umbilical vasculatures to angiotensin II and norepinephrine. Am J Physio 259:H197-H203

35. Reid IA 1992 Interactions between ANG II, sympathetic nervous system, and baroreceptor reflexes in regulation of blood pressure. Am J Physiol 262:E763-E778

36. Coote JH 1995 Cardiovascular function of the paraventricular nucleus of the hypothalamus. Biol Signals 4:142-149

37. Zhu GQ, Patel KP, Zucker IH, Wang W 2002 Microinjection of ANG II into paraventricular nucleus enhances cardiac sympathetic afferent reflex in rats. Am J Physiol 282:H2039-H2045 